\title{
Simulation Of High-Level
} Waste Treatment Process Trains At Idaho National Engineering And

\section{Environmental Laboratory}

T. T. Nichols

D. D. Taylor

L. Lauerhass

C. M. Barnes

March 2001

Idaho National Engineering and Environmental Laboratory Bechtel BWXT Idaho, LLC 
INEEL/EXT-01-00345

Revision 0

\title{
Simulation of High-Level Waste Treatment Process Trains at Idaho National Engineering \& Environmental Laboratory \\ - Scope-
}

\author{
T. T. Nichols \\ D. D. Taylor \\ L. Lauerhass \\ C. M. Barnes
}

Published March 2001

Idaho National Engineering and Environmental Laboratory High Level Waste Program Idaho Falls, Idaho 83415

Prepared for the U.S. Department of Energy Assistant Secretary for Environmental Management Under DOE Idaho Operations Office Contract DE-AC07-99ID13727 


\section{SUMMARY}

The purpose of this document is to provide the overall planning framework for the role of simulation in the integration/optimization of treatment process trains for the High Level Waste (HLW) Program at Idaho National Engineering and Environmental Laboratory (INEEL). This project involves a TTP (Technical Task Plan ID77WT31, Subtask C) with Savannah River Site (SRS) to jointly develop a simulation tool set that can support flowsheet optimization for HLW treatment trains at INEEL.

Despite the commonality between the simulation efforts at SRS and INEEL, the individual work scopes of the two sites are different - that of the INEEL is broader. This document concerns only the scope of the INEEL effort, and it describes the boundaries of several scope-related planning areas for this project at INEEL: 1) the objective of the project - the needs (drivers) the simulation efforts are attempting to satisfy, the role simulation results will play in managerial decision making, and the type of issues to be investigated; 2) constraints - higher-level budget forecasts and schedules, legal commitments, customer directives, and other similar forces that a priori define boundary elements; 3 ) the process domain - the set of chemical and physical operations to be modeled; 4) the model's life cycle - the phases of the waste treatment's life cycle that will utilize simulation, i.e., process configuration, design, and/or operations; 5) the types of models involved in the integrated simulation tool set - discrete vs. continuous, deterministic vs. stochastic, etc.; and 6) and targeted users - the downstream activities that may potentially use the simulation results.

This document closes with a description of the budget, schedule, and task inter-relationships that result from the determined scope. This document is the cornerstone of the planning process, and many of the software requirements flow directly from the decisions discussed in this document. 


\section{TABLE OF CONTENTS}

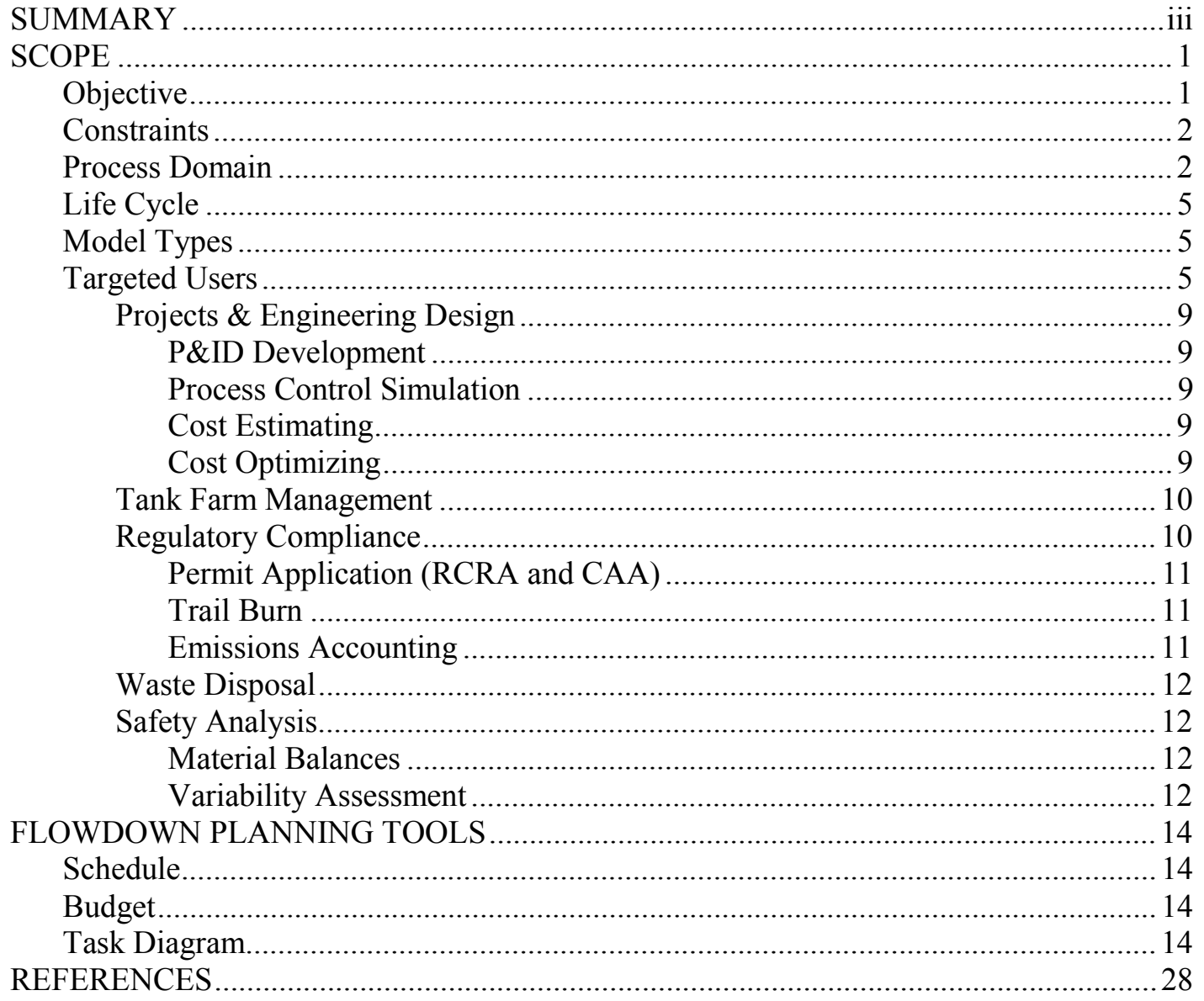

\section{TABLES}

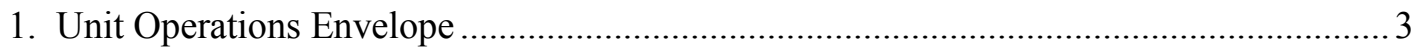

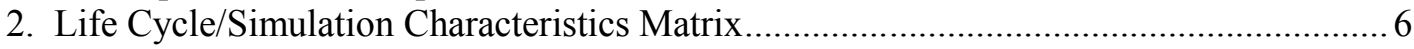

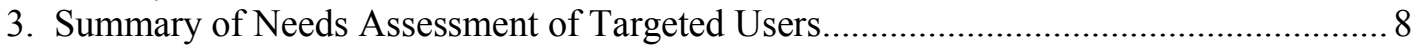

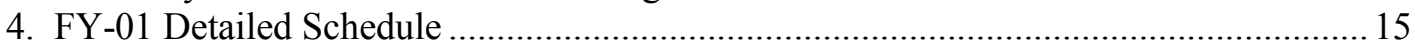

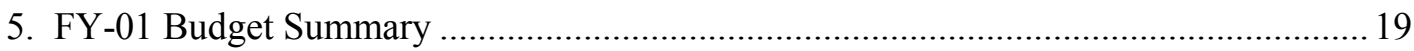

\section{FIGURES}

1. Top-Level Functional \& Data Flow Diagram for INEEL Treatment System

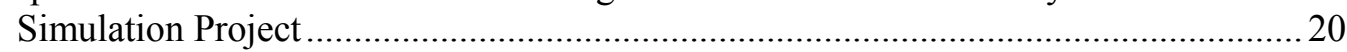

2. Diagram for "Develop INEEL Software Specification" Function ................................. 21

3. Diagram for "Develop Physical Properties Database Requirements" Function............... 22

4. Diagram for "Develop Performance Requirements" Function .....................................22

5. Diagram for "Develop Quality Requirements for Custom Code/Database" Function.... 24

6. Diagram for "Simulate INEEL Treatment System" Function........................................25

7. Diagram for "Code \& Integrate Custom Software \& databases" Function......................26

8. Diagram for "Document Current Knowledge \& Capability" Function............................. 27 


\section{SCOPE}

The scope of this project encompasses all that is involved in quickly developing an effective simulation tool set that can support the optimization of HLW treatment at INEEL. Simulation capability to support conceptual and detailed design of SBW treatment desired because of the aggressive schedule to treat all SBW by 2012. To maximize the benefit of the tool set, all reasonable attempts will be made to leverage economies of scope with other important analytical and reporting efforts within the HLW Program and INEEL. The wastes whose treatment will be simulated are SBW, NGLW, tank heels, and solid calcine. Debris treatment and HEPA filter leach will not be simulated, nor will off-site treatments.

The on-site handling of all primary and secondary streams for the waste envelope will be simulated in an integrated manner so that the system-wide impact of local changes (i.e., at individual unit operations) can be assessed and the entire treatment system optimized. Consequently, off-gas treatment and the operations of LET\&D, PEWE, HLLWE, and the Tank Farm will be modeled. Table 1 lists the unit operations required to simulate the entire alternatives envelope for SBW, NGLW, tank heels, and solid calcine.

The tool set will support the entire synthesis/optimization life cycle from process configuration in early design to continuous improvement during operations. This is a broader scope than that of Technology Development's current simulation efforts. In particular, the following activities are being considered for simulation's role based upon discussions with potential end-users: 1) expand low-level unit operations modeling support to Tank Farm management; 2) support process control design; 3) perform concurrent process/cost optimization; 4) provide emissions estimates for permit applications; 5) provide planning basis for trial burns; 6) calculate emissions that are physically unmeasurable on a continuous basis; and 7) support safety analysis by quantifying process/operational variability via dynamic simulation.

Simulation will not be used as a formal part of waste form qualification (Nichols, 2000b). It is expected that the tool set will contain several simulators: one steady-state and one transient for process modeling; a discrete-event simulator for operations modeling; and a process control simulator if such capability doesn't exist in the transient process simulator. The bulk of the software costs will accrue from the process simulators because discrete-event simulators and software for process control design are relatively inexpensive.

The individual elements of the scope are described in more detail below.

\section{Objective}

The objective of this simulation project is to create the capability at INEEL to perform integrated optimization of HLW treatment trains. Such capability is required to reduce life-cycle schedules and costs of HLW projects, which is imperative given the Settlement Agreement commitments and shrinking DOE budgets. Currently there are no plans for any type of integrated pilot plant demonstration of the process, which increases the role of process simulation. The joint TTP with SRS allows INEEL to leverage the experience of SRS in integrated, steady state, and dynamic process development to enhance and ensure similar capability at INEEL.

The results of the simulation tool set developed, being for the most part quantitative and lower level in nature, will be used by engineers and scientists to develop higher-level recommendations for DOE-ID and INEEL program managers regarding the treatment of HLW. As such, it is expected that 
technical personnel will be the primary end-users of simulation results, and program management will be an indirect end-user.

It is considered unwise to search for one simulation tool that can be all-things for everybody. From past experience, by the time the one simulation approach is developed it has usually been so expensive and taken so much time that it has lost focus and backing. Each individual study is unique enough such that the simulation becomes bogged down with the allfor-everybody model's simultaneous focus on decision levels and unit operations outside the particular study. One simulation package for all of INEEL, or all of HLW Program's needs for that matter, is not the desire of this project. Quickly developing an effective simulation tool set that can optimize HLW treatment by leveraging economies of scope with other important analytical and reporting efforts within the HLW Program, INEEL, and DOE Complex is the goal of this project.

\section{Constraints}

Existing legal agreements (Settlement Agreement, 1995; Second Modification, 1998) have aggressive milestones for ceasing use of the tank farm and treating the liquid waste. Simulations using the integrated tool set will commence at the beginning of FY-02 and be used to support conceptual and detailed designs for SBW treatment.

\section{Process Domain}

The simulation efforts seek to support the development of treatments for solid calcine, SBW, NGLW, and tank heels that will occur at INEEL. The main alternatives for treatment of these wastes currently involve vitrification, separations (UNEX, TRUEX, or SREX), ion exchange, grout, and calcine dissolution. The chemical and handling processes involved with these technologies are summarized in Table 1 and constitute the process envelope for the simulation effort. The process domain encompasses the entire INEEL treatment train, which includes the chemical processing, storage, movement, and handling of primary and secondary waste streams.

The primary focus of the simulation efforts will be on the chemical/treatment processes. However, logistical functions such as the storage, movement, and handling of materials will be included to tie processes together and accurately represent inter-process dependencies so that overall system performance can be assessed and optimized. Excluding such logistics would result in a loss of integration and defeat the purpose of this project. As such, models of logistical activities will be of less mathematical rigor than those of chemical processing unit operations, and they will tend to be closer to "black box" models than to models based on first principles.

The tool set needs the capability to model numerous ancillary equipment because the simulation efforts will support detailed design. Simulating the treatment of HEPA filters and contaminated debris is currently outside the scope of this project, as are off-site treatment and handling. 


\section{TABLE 1: UNIT OPERATIONS ENVELOPE}

\begin{tabular}{|c|c|}
\hline Process Type & Process/Operation $^{1}$ \\
\hline \multirow{4}{*}{ Drying } & Crystallizer \\
\hline & Solids Dryer (Ex. - Rotary Wiped Film, Hollow Flight) \\
\hline & Spray Dryer \\
\hline & $\begin{array}{ll}\text { Evaporator } \\
\\
\bullet \quad \text { PEWE } \\
\text { - HLLWE }\end{array}$ \\
\hline \multirow{11}{*}{ Separation (Physical) } & HEPA Filtration \\
\hline & Centrifuge \\
\hline & Film Cooler \\
\hline & Sintered Metal Filter \\
\hline & $\begin{array}{l}\text { Scrubbers (for particulate removal) } \\
\text { - Steam Atomized (Jet Hydrosonic or Free Jet) for very small size } \\
\text { - } \quad \text { Venturi for small size } \\
\text { - } \quad \text { Packed bed for coarse size }\end{array}$ \\
\hline & Sand Filter \\
\hline & Cyclone Separator \\
\hline & Bag House \\
\hline & Settling Tank - Decantation \\
\hline & $\begin{array}{l}\text { Liquid Filtration (solids removal) } \\
\text { - Diffusion (cartridge-type filters) } \\
\text { - Sieve (sintered metal type filters) } \\
\text { - Hybrid (cross-flow, spin-jet, etc.) }\end{array}$ \\
\hline & Grinder \\
\hline \multicolumn{2}{|l|}{$\begin{array}{l}\text { Separation } \\
\text { (Thermodynamic) }\end{array}$} \\
\hline \multirow{3}{*}{ Gas-Solid } & Thermal desorption ( $\mathrm{Hg}$ from $\mathrm{GAC} / \mathrm{S})$ \\
\hline & Thermal decomposition (Hg from GAC/S) \\
\hline & Adsorption (silver zeolite trap, silica gel trap) \\
\hline \multirow{5}{*}{ Gas/Solid/Liquid } & Spray Quench \\
\hline & Scrubber (venturi, submerged bed) \\
\hline & Mist Eliminator \\
\hline & KO Chiller \\
\hline & Fractional Distillation (LET\&D) \\
\hline Ionic Sorption & Ion Exchange \\
\hline Liquid-Liquid & Liquid/Liquid Extraction - Centrifugal Contactors \\
\hline \multirow[t]{2}{*}{ Homogenization (Mixing) } & $\begin{array}{l}\text { Makeup (blending of liquid/liquid, liquid/solid reagent, solid/solid feed } \\
\text { streams) }\end{array}$ \\
\hline & Suspension (sparging or blending of solids with liquid) \\
\hline
\end{tabular}




\begin{tabular}{|c|c|}
\hline \multirow{13}{*}{ Reactors } & Direct-Fired Combustion (Noxidizer reduction chamber) \\
\hline & Noxidizer Oxidation Chamber \\
\hline & $\begin{array}{ll}\text { Dissolution } \\
\text { - } & \text { Calcine } \\
\text { - } & \text { Cesium impregnated AMP from inert PAN substrate }\end{array}$ \\
\hline & HEDPA Oxidation \\
\hline & Neutralization \\
\hline & Sugar/Nitric Acid (Vitrification Feed Tank) \\
\hline & Aqueous Phase Precipitation of Mercury \\
\hline & Dioxin/Furan Formation (can occur in bag house, scrubber, or quench) \\
\hline & Dry Scrubber/Reactor \\
\hline & Calciner/Incinerator \\
\hline & Grouting \\
\hline & Electrochemical Reduction \\
\hline & $\begin{array}{cl}\text { Melter } & \\
- & \text { Induction } \\
- & \text { Joule-Heated } \\
\end{array}$ \\
\hline \multirow[b]{3}{*}{ Handling } & $\begin{array}{l}\text { Tank System } \\
\text { - Storage Tank } \\
\text { - } \text { Cooling-Jacketed Mixing Tank } \\
\text { - INTEC Tank Farm } \\
\end{array}$ \\
\hline & $\begin{array}{l}\text { Calcine } \\
\text { - Transfer } \\
\text { - INTEC Bin Sets }\end{array}$ \\
\hline & $\begin{array}{l}\text { Waste Packaging \& Shipping } \\
\text { - } \text { TRU solids } \\
\text { - } \text { LLW solids } \\
\text { - HLW solids } \\
\text { - UDS particulate solids } \\
\text { - Spent GAC } \\
\text { - Solid Hg } \\
\text { - PAN into High Integrity Container (HIC) }\end{array}$ \\
\hline \multirow[b]{2}{*}{ Heat Exchange } & Direct Injection Cooler (denoxidizer cooling chamber) \\
\hline & $\begin{aligned} & \text { Heat Exchangers } \\
& \text { - } \text { Condensers } \\
& \text { - } \text { Superheaters } \\
&\end{aligned}$ \\
\hline Ancillary Equipment & Feed hopper, conveyor, blower, filter, gas mixer, pump \\
\hline
\end{tabular}

${ }^{1}$ Barnes, 2000; Nichols, 2000a; Raytheon, 2000. 


\section{Life Cycle}

Table 2 shows the relationship between a treatment alternative's life cycle and the characteristics of corresponding simulations. Because of the tight process development schedule required to meet the 2012 date, the first use of the simulation tool set will be to support the conceptual and title designs for SBW treatment. However, it is expected that the involvement of the simulation tool set will span all life cycle phases - starting with process configuration for calcine treatment and extending through operations for both SBW and calcine treatment. Simulations will also be used to support some or all life cycle phases of NGLW and heel treatment. Consequently, the capability of the simulation tool set needs to encompass the entire range of uses shown in Table 2: process synthesis, process and operation optimizations, process control design, and process improvement.

\section{Model Types}

The range of model types required to support the entire life cycle is broad, as shown in Table 2 . Simulations and the models they are based upon can be categorized by several classification schemes, but the "Type of Models" column in Table 2 was limited to three major concepts: the role of time (steadystate vs. transient), the representation of state variables (continuous vs. discrete-event), and the randomness of inputs (deterministic vs. stochastic). It can be seen from the table that the aggregate use of the simulation tool set over an entire life cycle requires both types of each classification concept. This suggests that more than one commercial software package may be required over the life of this project because the mathematical basis and solving algorithms tend to vary for different model types, and a model's code is generally written with a specific classification in mind. The software package used for process optimization, for example, may be different than that used for operation optimization because of the differences in the role of randomness and how state variables are represented.

\section{Targeted Users}

The scope of this project is determined in part by the potential users of the simulation results and the needs that such users expect the simulation tool to satisfy. A user set revolving around five functions has been identified: 1) projects and engineering design, 2) Tank Farm management, 3) regulatory compliance, 4) waste disposal, and 5) safety analysis. Projects \& design and Tank Farm management are currently the main downstream HLW users of process simulation results. It is felt that the role of simulation may beneficially be expanded in all five areas.

A summary of the results of an initial needs assessment performed with representative personnel from each of the targeted functions is given in Table 3. Each of the potential synergies identified will be part of the scope of the simulation tool set unless further study concludes that it is infeasible or cost ineffective. The assessment results for each targeted user are presented below in more detail. 


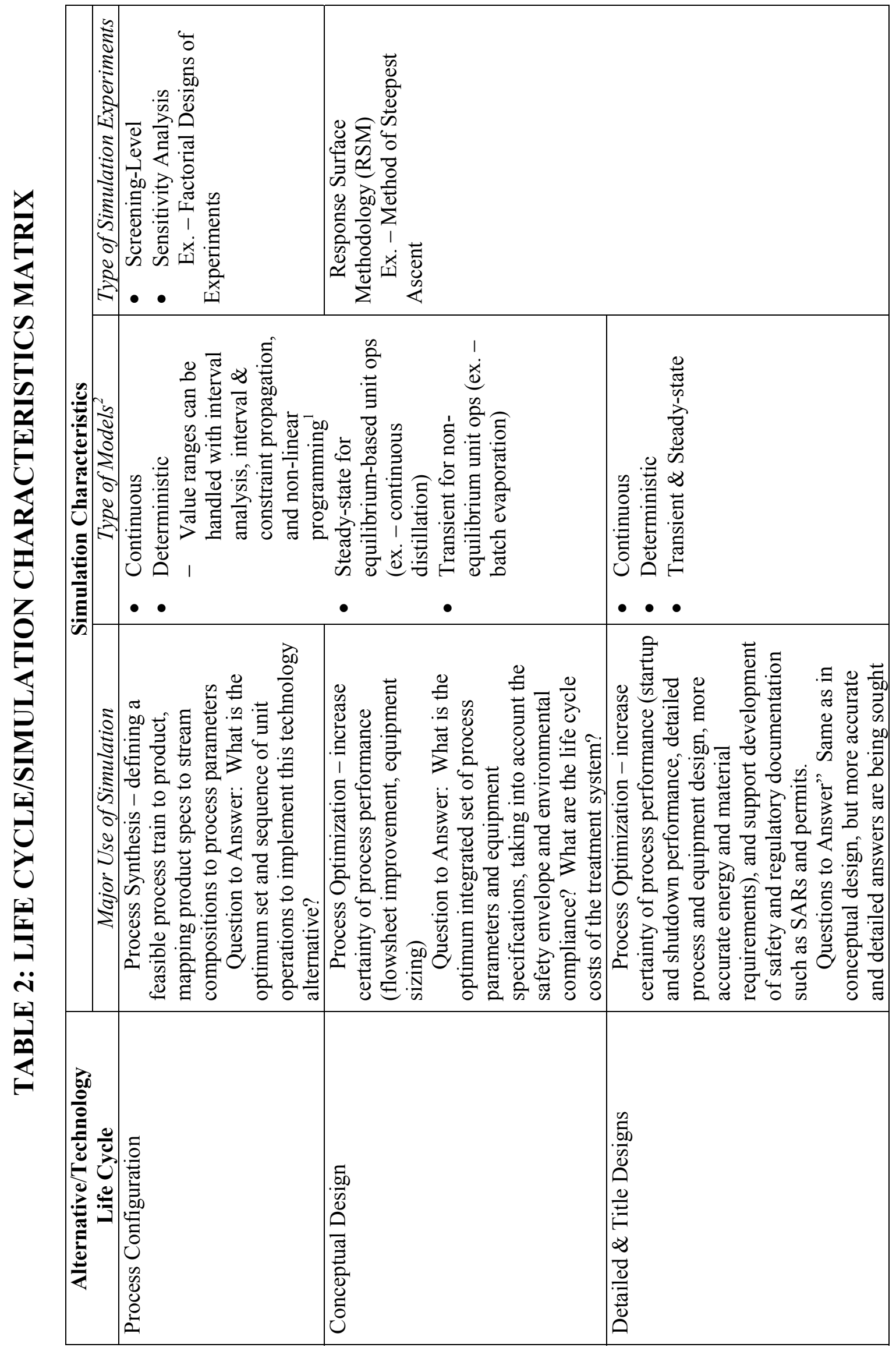




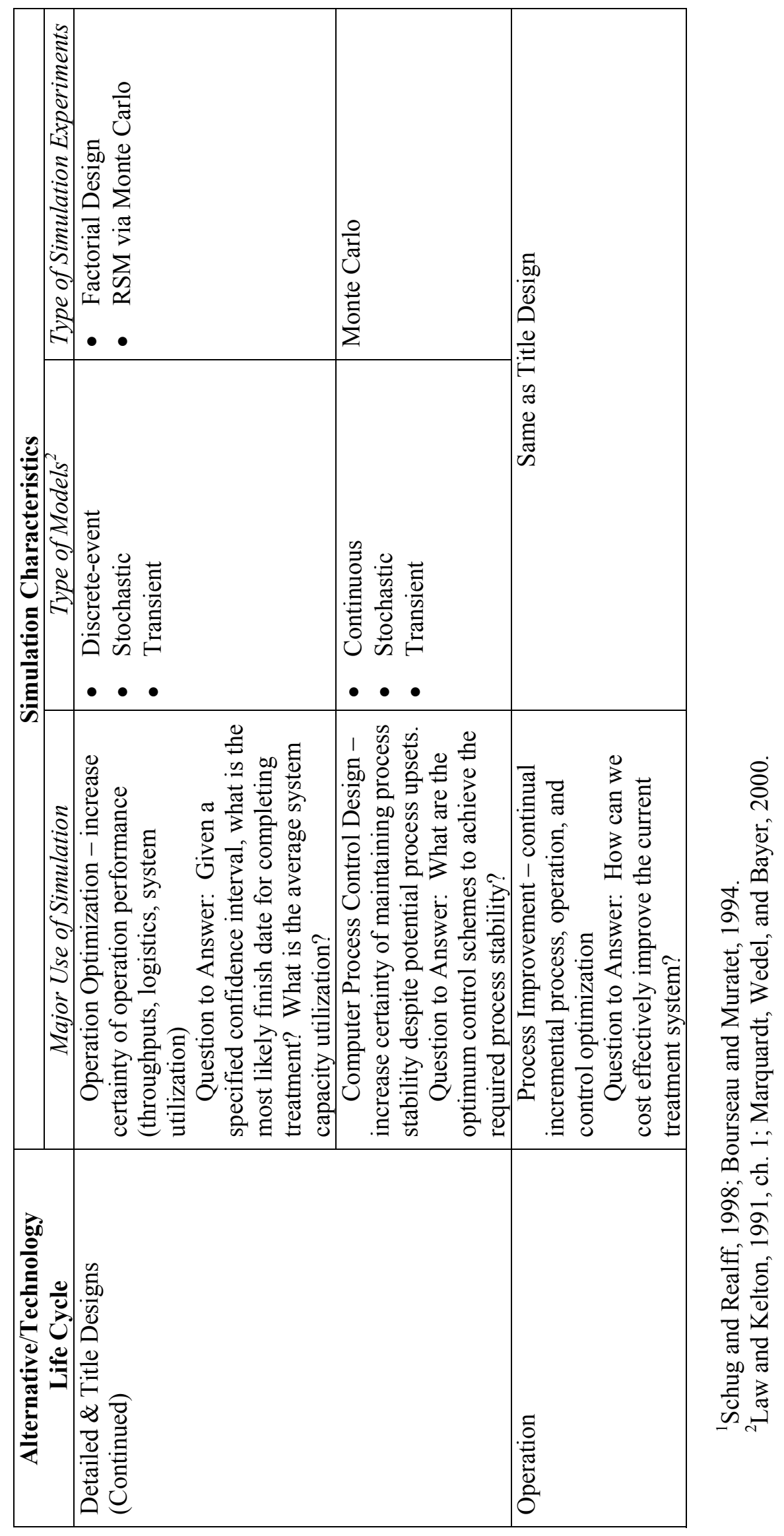




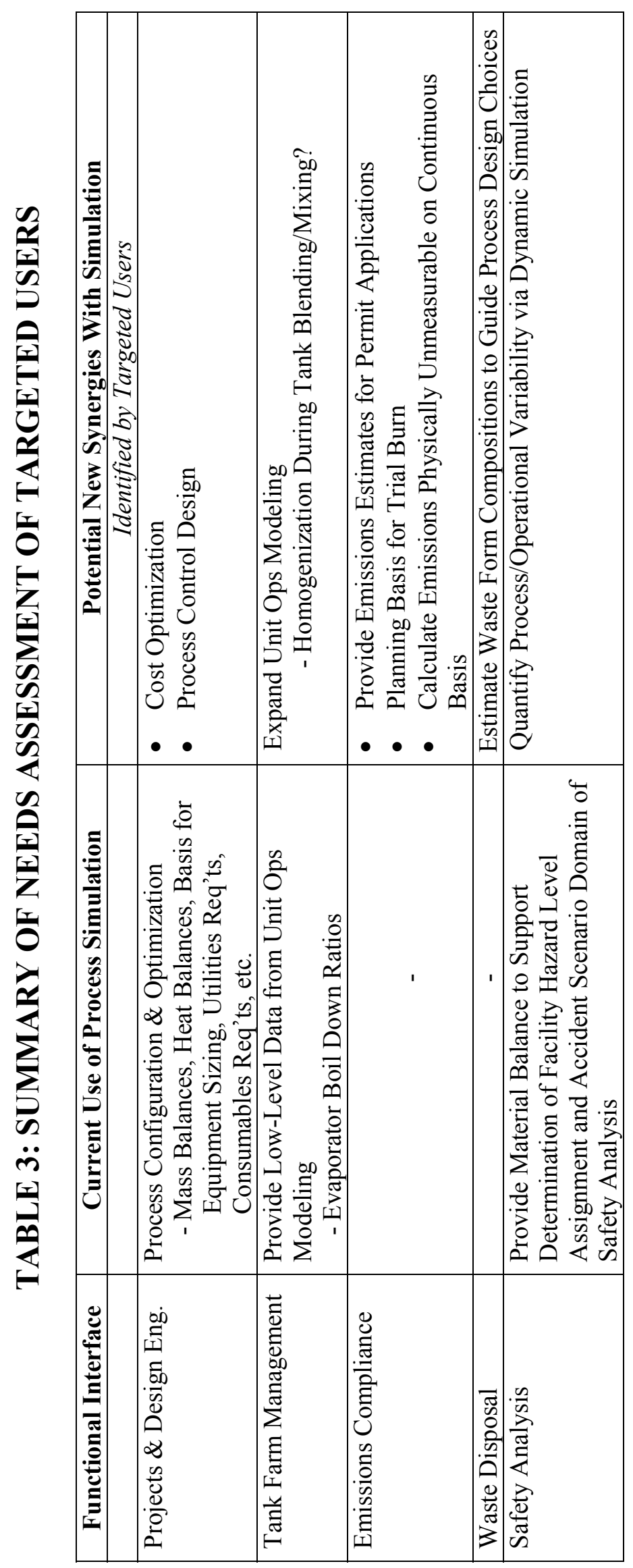




\section{Projects \& Engineering Design}

Project managers are less concerned with how the design engineers obtain their data then they are with assuring that the data is reliable. Consequently, project managers may not have a strong opinion regarding what role simulation does, could, or should have in design engineering.

A primary function of process simulation is to provide the basis for a design. This includes mass balances, heat balances, the basis for equipment sizing, utilities requirements, consumables requirements, etc. Besides maintaining these primary capabilities in process configuration and optimization, designers have expressed interest in pursuing the integration of simulation with two other design activities: cost optimization and process control design. Future discussions are planned to explore these potential synergies further. Designers feel that a simulation tool can neither appreciably facilitate P\&ID development nor reduce the workload of cost estimating. The potential benefits and disadvantages of the use of simulation in various design activities are detailed below.

P\&ID Development - Simulation engineers feel that process simulators capable of facilitating P\&ID development do exist and that designers should take advantage of such a labor- and time-saving opportunity. The designers, however, have a different perspective. Yes, It may be feasible to achieve graphical format compatibility and similarity in the icon set between the process simulator and the P\&ID generator. However, designers don't feel that it would be worthwhile to customize a process simulator to generate process flow diagrams for use by P\&ID designers because the creation of P\&IDs involves so much manual graphical manipulation by the draftsman. Designers feel that it probably wouldn't save much time compared to the draftsman starting from scratch. Consequently, the facilitation of P\&ID development is not part of the initial scope of the simulation tool set because of a lack of interest on the part of the end-user, the designer.

Process Control Simulation - Designers feel that having the capability to simulate the performance of process control schemes in a process simulator would be beneficial. This is not currently done to an appreciable degree.

Cost Estimating - There appear to be at least three reasons for not trying to achieve electronic handoff to cost estimating (CE). First, CE has a unique set of software and a unique cost accounting system. Designers doubt the feasibility of customizing a process simulator to generating electronic files compatible with the needs of cost estimating. Second, designers feel that having cost estimators doing the data entry is beneficial because it gives the estimators low-level knowledge of the underlying data and assumptions. Such familiarity would most likely be lost if the cost data were directly transferred from a simulator to CE's software.

The third reason is because estimating accurate absolute life cycle costs is hard to automate. This is due to several factors: 1 ) equipment costs are usually only about $30 \%$ of total capital costs; 2 ) equipment cost estimates of the accuracy level required for optimization can only be obtained by direct contact with vendors and quotes specifying the various cost factors (size, number of trays, etc.); 3 ) the previous two elements require that an optimizing routine with a cost objective function have accurate relationships for equipment cost vs. various cost factors and for equipment characteristics vs. other cost sources (facility structure, HVAC, materials, operations, etc.) - such relationships would be needed for each of the major pieces of equipment; and 4) inaccuracies in the relationship equations would probably introduce aggregate error greater than the increase in cost accuracy being sought.

Cost Optimizing - Because of the difficulties with estimating detailed absolute costs, cost optimizing is usually performed by designers supporting HLW Program mostly on an ad-hoc basis after process optimization has been performed. However, some designers and simulation engineers feel that 
there is benefit from pursuing integrated process/cost optimization because accurate absolute costs are not required. Optimization is comparative in nature, so differential costs are the key. Differential costs, requiring less rigor than absolute costs, can be adequately estimated with a consistent set of cost relationships. Consequently, it is felt that a process simulator with cost functionality could facilitate cost/benefit analysis and cost optimizations of processing alternatives.

\section{Tank Farm Management}

The objective of optimizing the treatment train requires that the simulation tool model at least the logistical tie between the Tank Farm and treatment processes since the Tank Farm supplies the feed to the various processes. That unquestioned basic tie is not the focus of the following paragraphs. This section discusses how the simulation tool can facilitate decision making regarding operation of the Tank Farm.

The main emphasis for Tank Farm operations is the optimization of the treatment of liquid wastes in the Tank Farm and closure flushing activities and schedule. The needs of the Program Office are relatively high-level; they involve analyzing tank blending and treatment options (including closure) in order to recommend scheduling scenarios. Such scenarios integrate Operations, Projects, long range objectives and milestones, and budgets. For example, Engineering (Nenni) does Aspen modeling of evaporating liquid wastes in PEWE and HLLWE for various blending scenarios and gives the corresponding boil down ratios to Program Office (Millet), who then uses them along with information from others such as Tank Closure (Quigley), Operations (Ward), Facility Disposition (Park) and Basin Management (Weidert) to estimate operational schedules. The schedules are then used by Program Office (Palmer) to estimate costs for the operational scenarios.

Management of the Tank Farm requires three broad categories of data needs and decision making: low-level (detailed), medium-level, and high-level (summary). Simulation of unit operations is low-level. The processing campaign schedules and costs estimates the Program Office develop are medium-level decision-making. Value engineering and brainstorming sessions involved in technology road mapping are examples of high-level decision making. The integration of these different levels of decision making across operations, technical, and program personnel requires much human interaction and human decision making that some feel should not be automated even if it could.

The main need of the Tank Farm management function for simulation appears to be to continue to provide accurate low-level data to support the higher levels of decision making. The benefit, if any, of expanding the role of simulation past the low-level analysis of individual unit operations or to increase the electronic integration with other decision making tools is not perceived at this time. This is due to the variable and continual nature of the data needs and decision making involved with managing the Tank Farm.

One type of low-level modeling that is currently not being performed but may be beneficial is tank blending, i.e., modeling the transient and spatial compositional profile during mixing that occurs when the contents of one tank are added to another, accounting for precipitation and gas formation. This could increase our understanding and prediction of heel compositions and the value of tank flushes, for example.

\section{Regulatory Compliance}

Regulatory compliance activities require quantitative measures of facility inventories and emissions of hazardous substances. Generally, actual measurements are needed to support claims of compliance with statutory limits on these quantities. However, there are situations (e.g., during preliminary stages of design) when actual measurements are not yet available even though regulatory 
groundwork must proceed (e.g. permit application preparation, submission, and review by regulatory agencies). In addition, some pollutant species may not be reliably measurable on a continuous basis in certain effluent streams. In situations such as these it is imperative that reasonable quantitative estimates be provided. So although simulation isn't currently used to support regulatory compliance, the need for such estimates underscores the potential utility of process simulation and modeling.

The potential role of simulation in permitting, trial burns, and emissions accounting is discussed below. Regulatory compliance personnel typically ask Projects to supply the technical data.

Consequently, the integration of simulation with the generation of compliance data in these three areas will be discussed with project and design engineers in the future.

Permit Application (RCRA and CAA) - It is expected that new HLW processing facilities will require both RCRA and Air permits from the State of Idaho. Such permits generally require that extensive process descriptions be provided which include quantitative descriptions of process streams, hazardous substance inventories (chemicals and radionuclides), and projected emissions. An Idaho stationary source air permit application, for example, requires:

"...descriptions, specifications, and drawings showing the design of the stationary source..., the nature and amount of emissions (including secondary emissions), and the manner in which it will be operated and controlled."( IDAPA 58.01.01.200.)

“...the applicant shall demonstrate preconstruction compliance with Section $161 \ldots$ 01. Identification Of Toxic Air Pollutants. The applicant may use process knowledge, ... to identify the toxic air pollutants emitted by the stationary source or modification. (6-30-95) 02. Quantification Of Emission Rates. (6-30-95)

a. The applicant may use standard scientific and engineering principles and practices to estimate the emission rate of any toxic air pollutant at the point(s) of emission. (6-30-95)" (IDAPA 58.01.01.210.)

The aggressive schedule for processing of INEEL waste makes it likely that permit applications will have to be prepared and submitted without actual data from pilot operations to support emissions estimates. Thus, such estimates will likely come from process simulations. Since the plant will be permitted on the basis of emissions rates stated in the permit application it is desirable that the process simulation be accurate. This would minimize post-construction retrofit of processes to achieve projected emissions rates stated in the permit application.

Trial Burn - Since a glass melter is a thermal waste treatment device it is likely to be regulated similarly to an incinerator. Thus, a trial burn will be performed prior to actual waste processing operations to demonstrate compliance with emissions limits. In addition the trail burn operating conditions will establish the operating limits of the melter allowed under the operating permit. This being the case, it is essential that the trial burn be carefully planned so that waste treatment operations are not unnecessarily restricted. Process simulation will provide the planning basis for the trial burn. This basis will include mass balances and projected effluent stream compositions and flow rates. The planning basis will likely be validated by performing a "pre-burn" test prior to the actual trial burn. As with the permit application discussed above, the fidelity of the process simulation used for the planning basis will have a significant impact. It will determine the modifications that will be needed to the burn plan and/or actual processing equipment before a trial burn can be performed. In addition the simulations will indirectly impact operations because of the fact that operating parameters are fixed by the trial burn.

Emissions Accounting - During design of the waste processing facility process simulation will be used extensively to estimate emissions of regulated pollutants. Such estimates will be used to select and 
optimize off-gas system components, and to establish operating envelopes. It is also possible that, after facility startup, accounting of some regulated emissions that are not directly measurable would be done with process simulation. For example, high $\mathrm{NO}_{2}$ levels in the off-gas made it difficult or impossible to obtain representative off-gas composition measurements from the New Waste Calcining Facility at INTEC until recently. In this case, process simulation might be utilized (subject to its acceptance by the state) to demonstrate compliance with mandated emissions limits.

\section{Waste Disposal}

Treated waste will ultimately be disposed at a suitable repository (e.g., WIPP, Yucca Mountain, Hanford Disposal Site, etc.). Each site has its own criteria and procedure for waste acceptance. Waste certification procedures vary from one disposal facility to another. For example, waste sent to WIPP from the INEEL TRU Waste Program undergoes real-time radiographic inspection, statistical sampling, and characterization based on process knowledge, and selective sampling. High level vitrified waste from the Savannah River Site is qualified for acceptance indirectly through qualification of the process that produces it. At present the final disposal location(s) for treated INEEL HLW is unspecified. However, based on the waste acceptance protocols for WIPP and Yucca Mountain, it is presumed that treated waste characteristics calculated on the basis of process simulation would not be used directly to demonstrate compliance with disposal site waste acceptance criteria. The process simulator would be used in design and optimization of the treatment process. It would also support operations and possibly provide estimated feed compositions for use in process control, batching, etc. However, we assume that any process model that would be used in conjunction with process qualification to indirectly qualify treated waste for disposal (as at SRS) would be an independent statistical model developed for the purpose of directly mapping from process parameters (e.g., feed composition, processing temperatures, residence times, etc.) to waste product quality (leachability, phase characteristics, etc.). Such a model may be part of (or accessed by) the process simulator, but would be developed, validated, and qualified independently. For the purposes of scoping the current project it is assumed that use of the process simulator in qualifying treated waste for disposal would be limited to an indirect role in the areas cited above, namely, process/flowsheet design and operations support.

\section{Safety Analysis}

Safety analysis of a process involves identification of the accident potential for the process and determination of the Facility Hazard Level as nuclear (Level 1, 2 or 3) or non-nuclear (High, Moderate, Low). Input from process engineers knowledgeable with the facility design and process operation is critical in identifying potential accident scenarios and consequences. Steady-state simulation is currently used to determine material balances, and utilizing dynamic simulation to assess process and operational variability will be pursued in the future. Material balances and variability assessment are discussed in more detail below.

Material Balances - The starting point for determining the significance and potential for accidents is the material balance based upon the process flow diagram together with planned tank storage. These estimates provide the quantities of chemicals, radionuclides, and fissionable materials anticipated in the facility, which are compared with threshold quantities (defined in relevant DOE Orders) to establish the Facility Hazard Level. The accuracy of the material balance should be sufficient to determine if individual component threshold limits for classifying the facility are exceeded. Steady-state simulation is usually performed to help determine these fundamental mass balances.

Variability Assessment - Safety analysis takes into account a number of factors other than the material balance. These factors include process feed variability, operating conditions (temperature, pressure), the chemical compatibility of streams in the facility, shielding provided, amount of energy 
utilization, potential for achieving nuclear criticality, and any special facility operations for material movement. It is felt that dynamic simulation, which is not currently being performed, could help determine the process and operational variability. 


\section{FLOW DOWN PLANNING TOOLS}

The scope, as determined above in the elemental break down, leads to a preliminary budget, schedule, and task set.

\section{Schedule}

A detailed schedule for FY-01 is presented in Table 4. The main task identifiers A-D are from the corresponding TTP. Activities with names prefixed by hierarchical numbers of level three are shared with a supporting EM-40 Work Package. Numbers in parenthesis at the end of a task name refer to the corresponding task identifier on the data flow diagram (discussed below). Dates corresponding to TTP milestones are highlighted in red.

\section{Budget}

The year's summary budget is shown in Table 5. The tasks and dollars shown in the schedule and budget are only for those INEEL efforts that have a direct tie to this project's scope. Neither other INEEL activities that have independent drivers but support and interface with the scope of this project nor the efforts and scope of SRS are accounted for in the schedule and budget shown here. Calcine, heel, and SBW characterization, for example, aren't accounted for in Tables 4 and 5, but they are tasks that impact INEEL HLW flowsheet optimization.

\section{Task Diagram}

A functional and data flow diagram detailing the relationships between the activities involved in executing this project is displayed in Figures 1-8. These figures show the relationships between various tasks by highlighting the chronology, requisite data flows, and feedback loops. Gross chronology is indicated left to right. Consequently, vertical alignment of tasks indicates they can be performed in parallel while horizontal placement implies sequencing.

The 5-level hierarchical blocks have many associated data flows because they involve integration activities. For example, the initial needs assessment of targeted users discussed previously is part of the 5.7 function block, which was performed simultaneously with the 1.0 function block - Develop Simulation's Scope. This scoping document is the main output of the 1.0 block which flows into the 2.0 block, Develop INEEL Simulation Software Specification.

A feedback loop is apparent between the actual simulations and several of the integration efforts. Simulation results flow from the 4.0 block into the integration blocks of Cost Estimating (5.2) and Equipment Design (5.3), which in turn generate cost and schedule information for treatment scenarios which flows into the 5.5 block. This cost and schedule information could result in changes to the process alternatives envelope, which would ripple through the 2.0 and 3.0 blocks back down to the simulation 4.0 block. Similar circular relationships between simulation efforts and research (5.1) and our self-awareness (6.0) are shown in Figure 6. The functional and data flow diagram presented in Figures. 1-8 contains a level of detail sufficient to support FY-01 planning and was the basis for the task break down shown in Table 5. However, the diagram will be modified and added to with time - i.e., function blocks will be decomposed further if needed to facilitate detailed planning as the time for their execution approaches. 


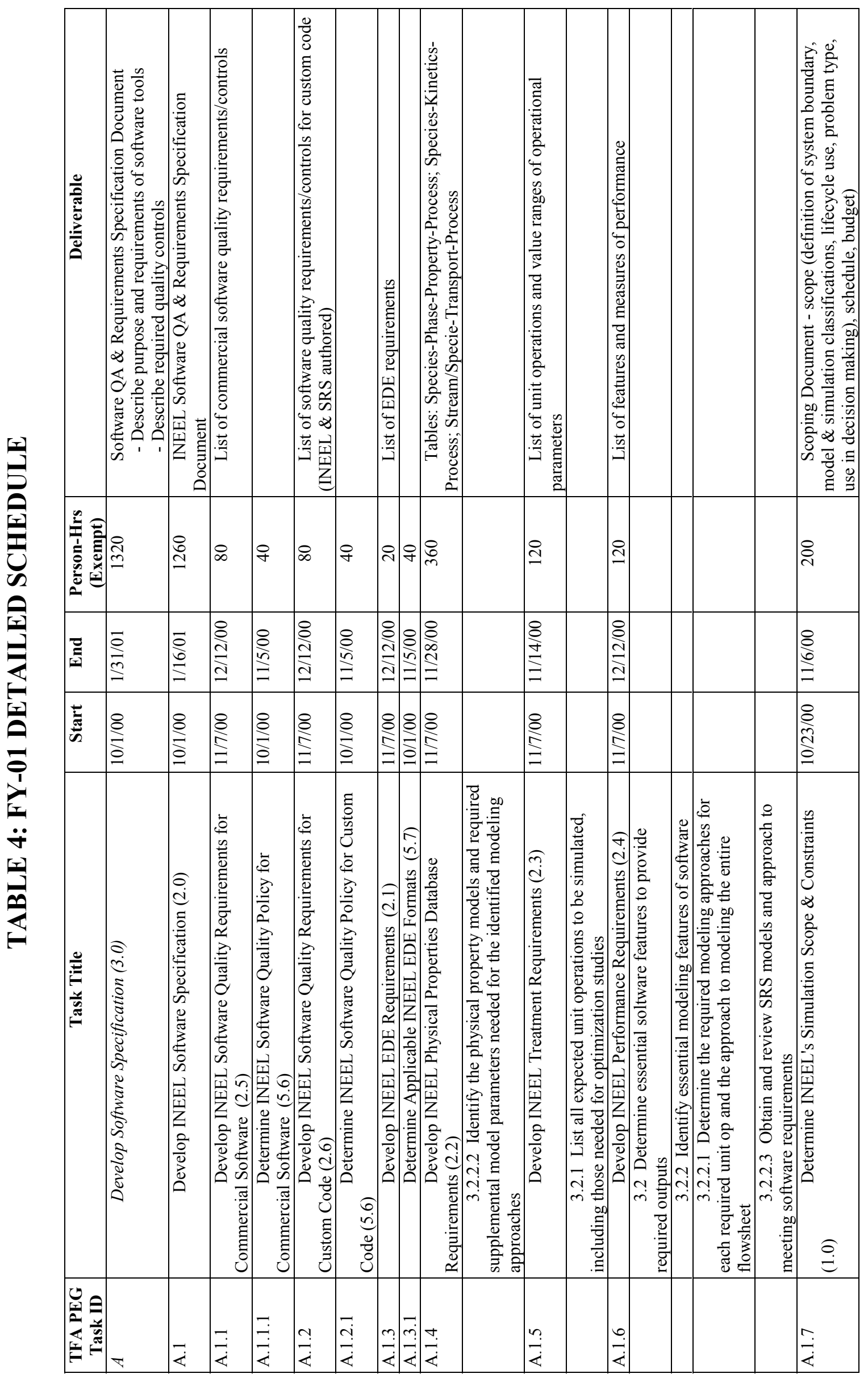




\begin{tabular}{|c|c|c|c|c|c|c|c|c|c|c|c|c|c|c|c|c|c|c|}
\hline 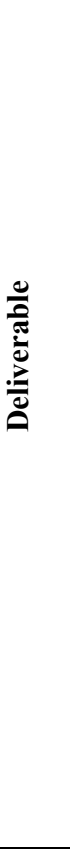 & & & & & & & & & & & 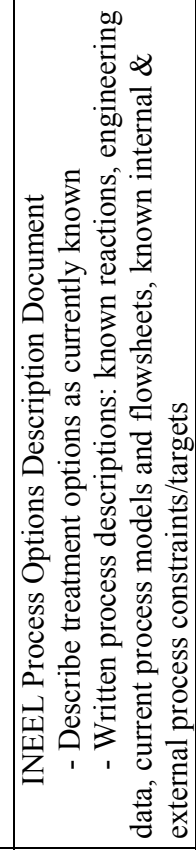 & 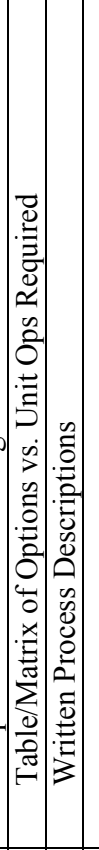 & & & & & & \\
\hline 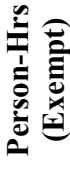 & & & & & & & & & 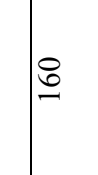 & 8 & $\stackrel{\infty}{2}$ & 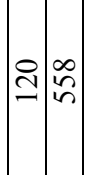 & & & & & & \\
\hline 矛 & & & & & & & & & 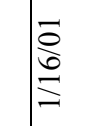 & 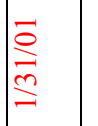 & 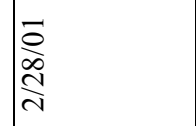 & 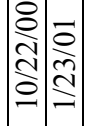 & & & & & & \\
\hline 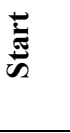 & & & & & & & & & 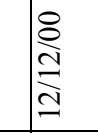 & $\stackrel{\Xi}{\stackrel{0}{\Sigma}}$ & $\stackrel{8}{2}$ & 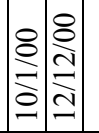 & & & & & & \\
\hline 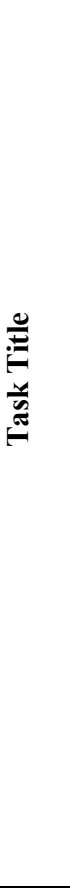 & 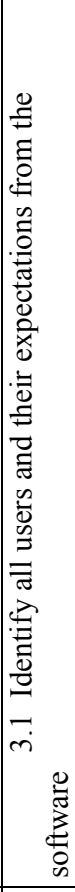 & 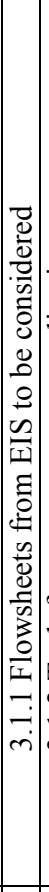 & 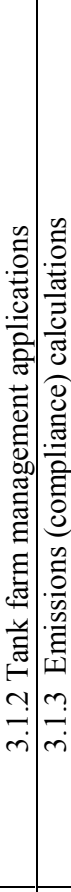 & 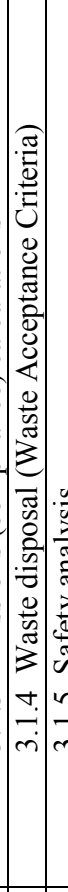 & 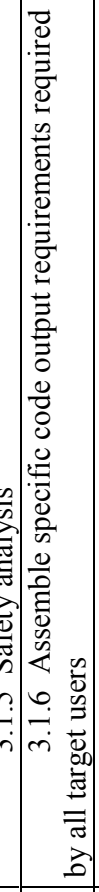 & 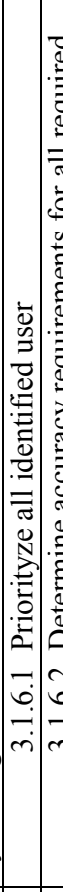 & 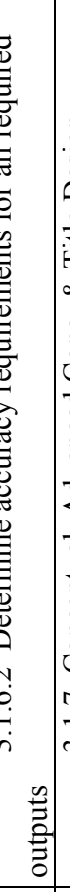 & 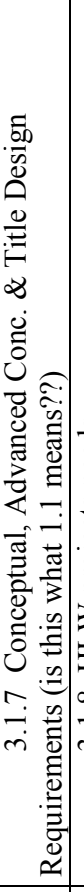 & 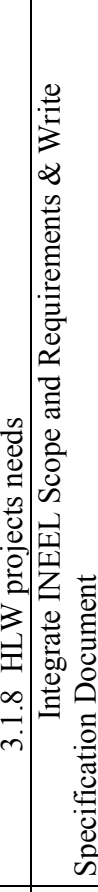 & 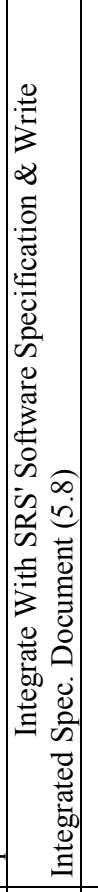 & 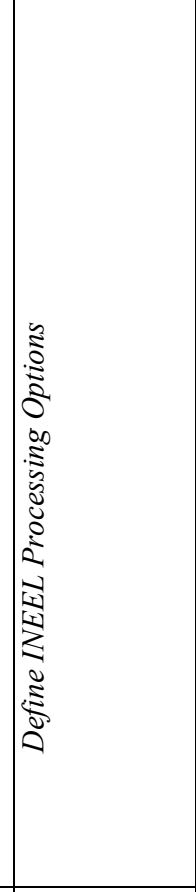 & 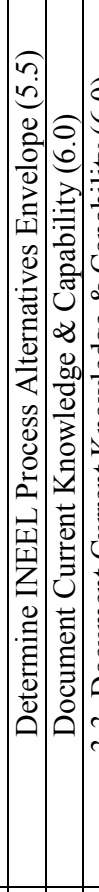 & 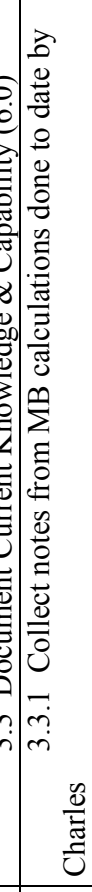 & 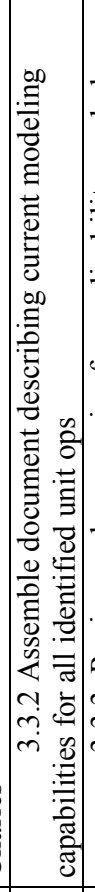 & 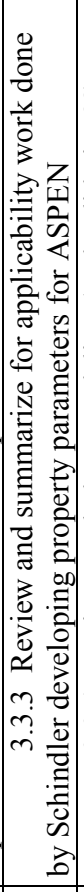 & 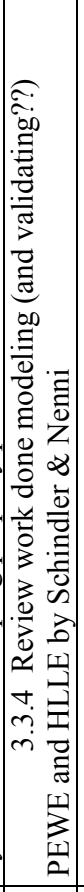 & 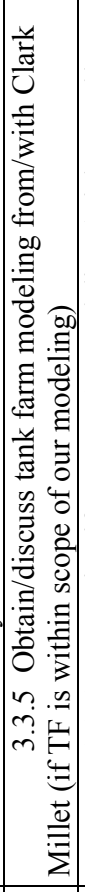 & 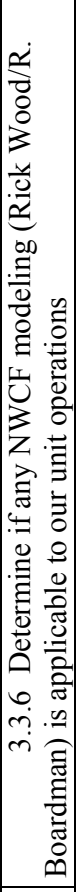 \\
\hline 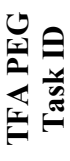 & & & & & & & & & $\dot{\dot{<}}$ & & $\infty$ & \begin{tabular}{l|l|}
$\bar{\infty}$ & $\tilde{\infty}$ \\
\end{tabular} & & & & & & \\
\hline
\end{tabular}




\begin{tabular}{|c|c|c|c|c|c|c|c|c|c|c|c|c|c|c|c|c|c|c|c|}
\hline 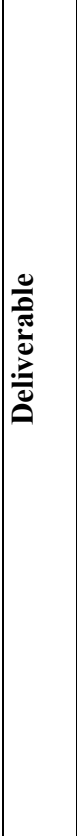 & & & 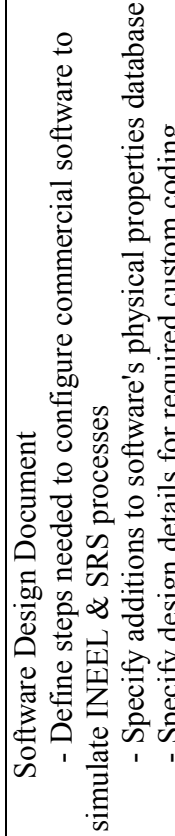 & 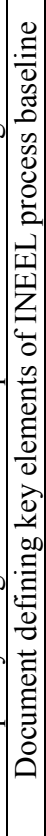 & & 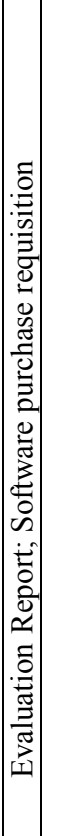 & & & & & & & & & & & 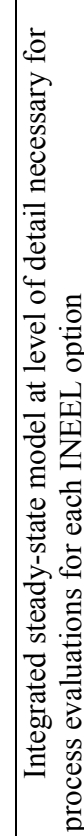 & 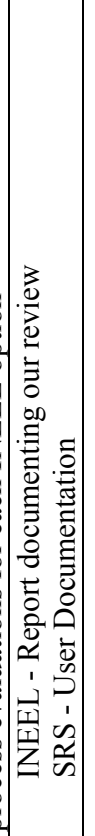 & \\
\hline 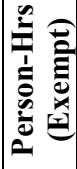 & & I & 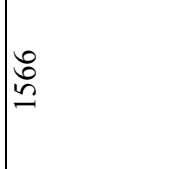 & $\mid \begin{array}{l}\infty \\
\sim\end{array}$ & & \begin{tabular}{|c|c}
0 \\
2
\end{tabular} \mid & & & & & & & & & $\stackrel{8}{8}$ & ఏ & 文 & $\stackrel{\infty}{8}$ & \\
\hline 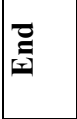 & & $\mid$ & $\frac{\vec{Q}}{\stackrel{\rho}{0}}$ & $\begin{array}{l}\vec{\rho} \\
\stackrel{\rho}{\rho} \\
\stackrel{f}{f}\end{array}$ & & $\begin{array}{l}\vec{D} \\
\stackrel{2}{f} \\
\vec{f}\end{array}$ & & & & & & & & & $\frac{\vec{\rho}}{\stackrel{\infty}{i n}}$ & $\begin{array}{l}\bar{b} \\
2 \\
0 \\
0\end{array}$ & $\begin{array}{l}\overrightarrow{0} \\
\stackrel{\partial}{0} \\
\alpha \\
\sigma\end{array}$ & $\frac{\vec{a}}{\frac{n}{a}}$ & \\
\hline 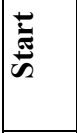 & & $\mid \begin{array}{l}\tilde{D} \\
\stackrel{+}{ \pm} \\
=\end{array}$ & $\frac{\vec{\rho}}{m}$ & 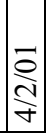 & & $\underset{m}{\stackrel{D}{m}}$ & & & & & & & & & $\underset{i}{\frac{5}{n}}$ & $\begin{array}{l}\bar{D} \\
\vdots \\
i \\
n\end{array} \mid$ & $\frac{\vec{\partial}}{\frac{\partial}{i n}}$ & $\frac{\bar{a}}{\frac{a}{n}}$ & \\
\hline 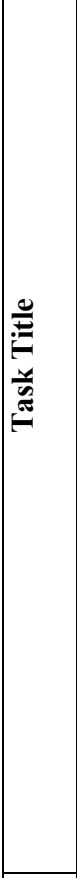 & 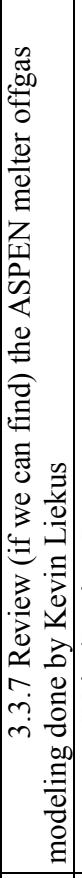 & 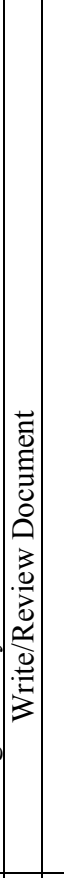 & 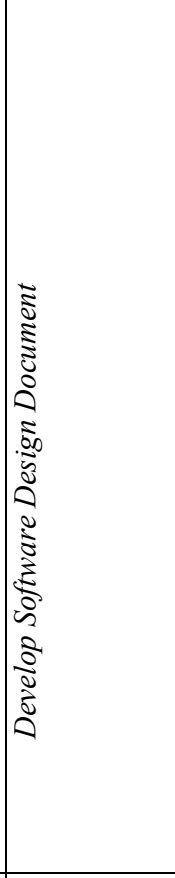 & 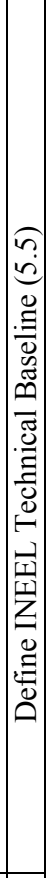 & 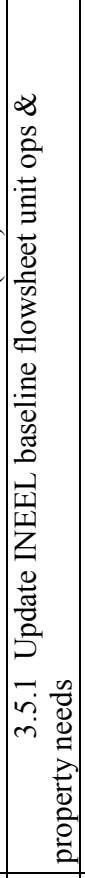 & 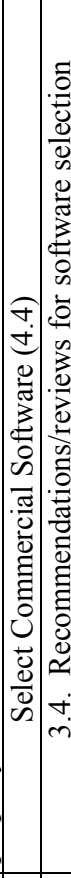 & 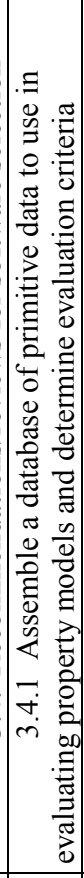 & 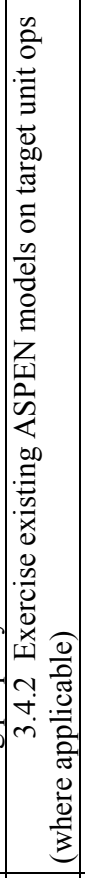 & 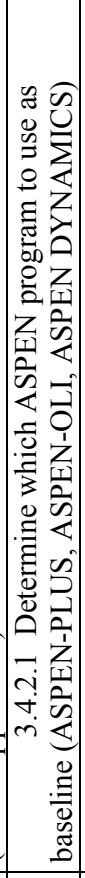 & 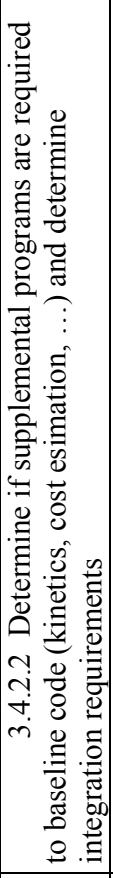 & 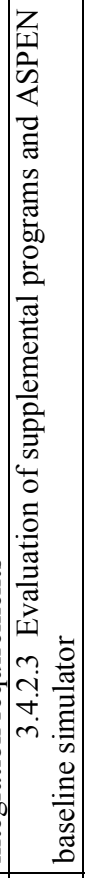 & 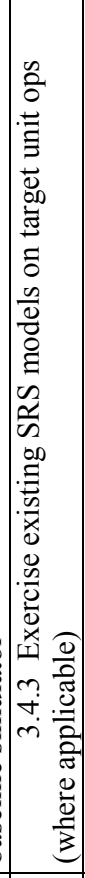 & 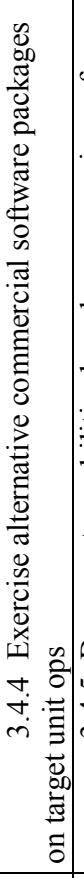 & 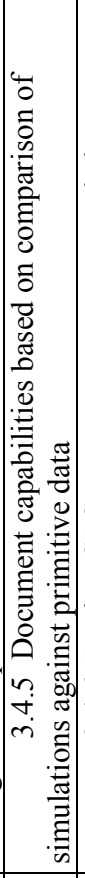 & 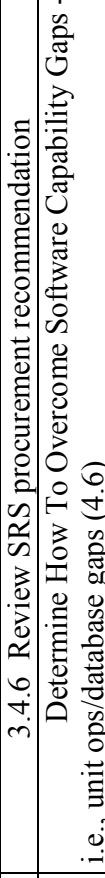 & 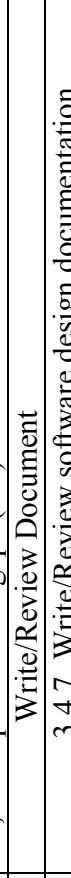 & 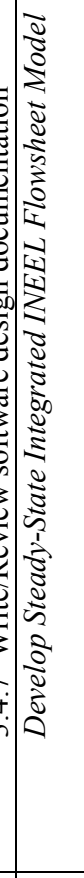 & 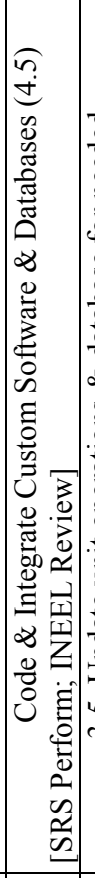 & 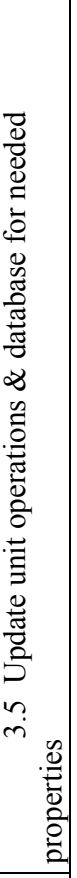 \\
\hline 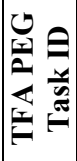 & & $\infty$ & U & 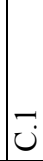 & & ن & & & & & & & & & ن & ن & $\theta$ & D & \\
\hline
\end{tabular}




\begin{tabular}{|c|c|c|c|c|c|c|c|}
\hline 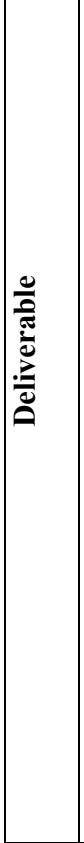 & & & & 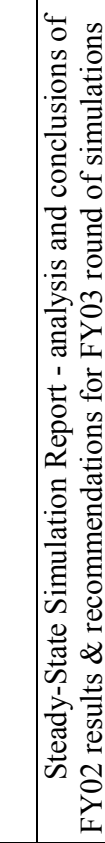 & & 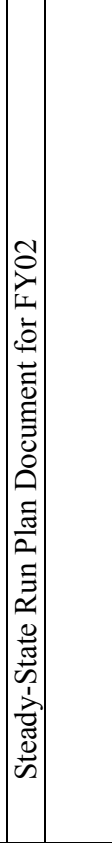 & 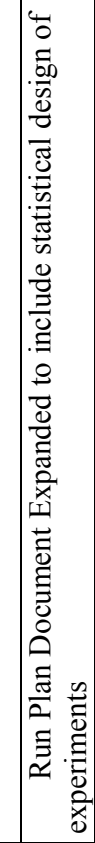 \\
\hline 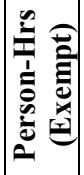 & & & & ஓ & $\infty$ & 응 & 8 \\
\hline$\underset{\underline{\mathbf{s}}}{\mathbf{E}}$ & & & & 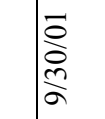 & $\frac{\vec{D}}{0}$ & $\left|\begin{array}{c}\vec{\rho} \\
\infty \\
\infty \\
\infty\end{array}\right|$ & 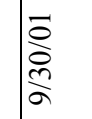 \\
\hline 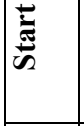 & & & & $\frac{\overrightarrow{2}}{\frac{n}{6}}$ & $\frac{\overline{0}}{\frac{0}{2}}$ & $\mid \begin{array}{c}\bar{a} \\
\frac{1}{n}\end{array}$ & $\underset{\infty}{\stackrel{\sigma}{a}}$ \\
\hline 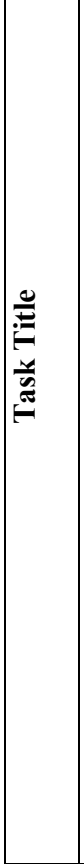 & 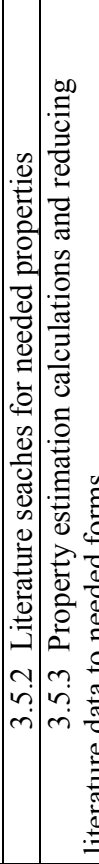 & 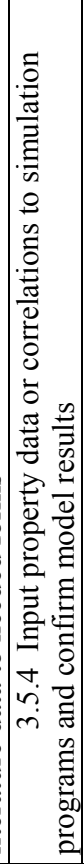 & 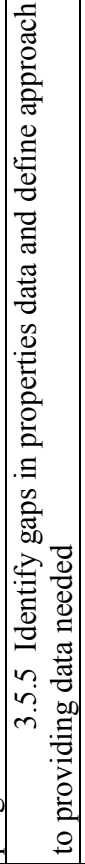 & 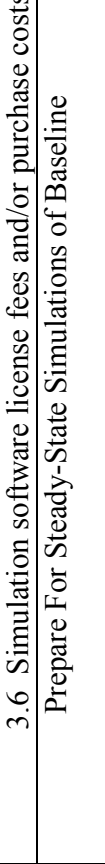 & 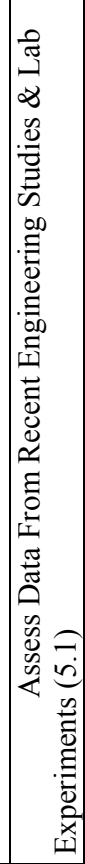 & 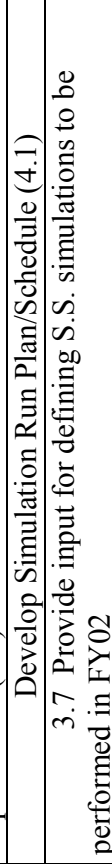 & 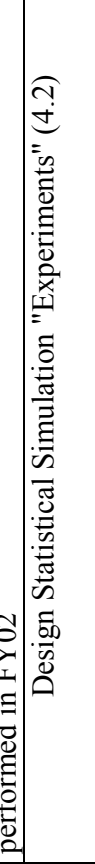 \\
\hline 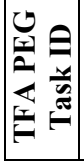 & & & & 0 & 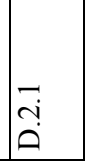 & $\mid$\begin{tabular}{c}
$\mathfrak{a}$ \\
\hdashline
\end{tabular} & $\stackrel{c}{\ddot{n}}$ \\
\hline
\end{tabular}




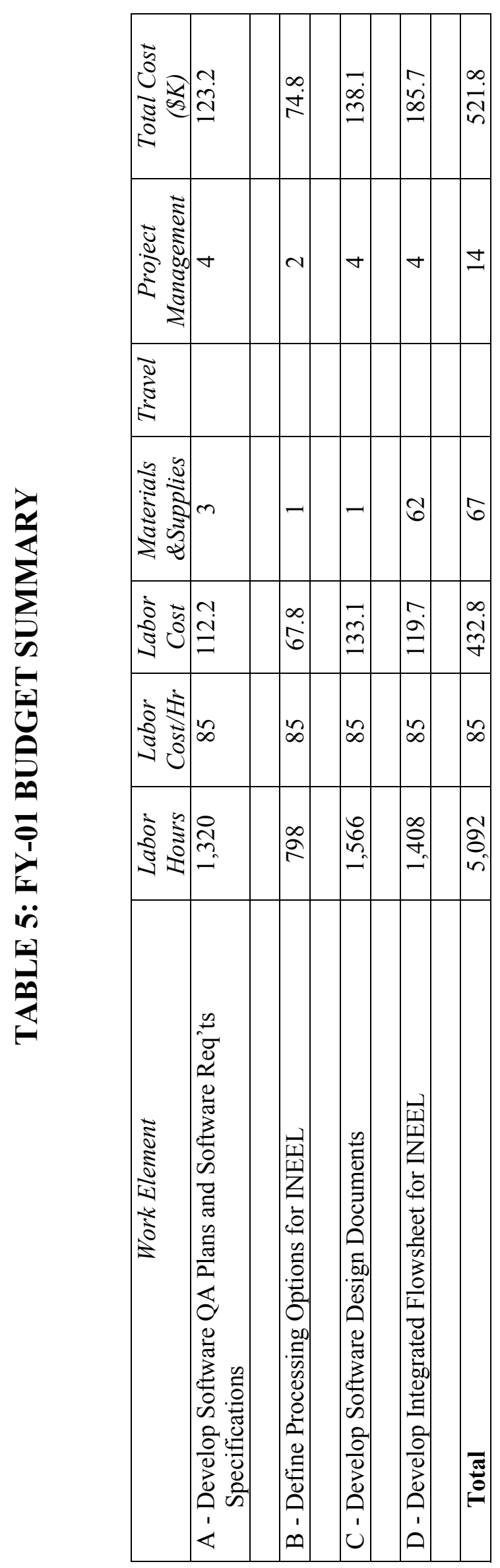




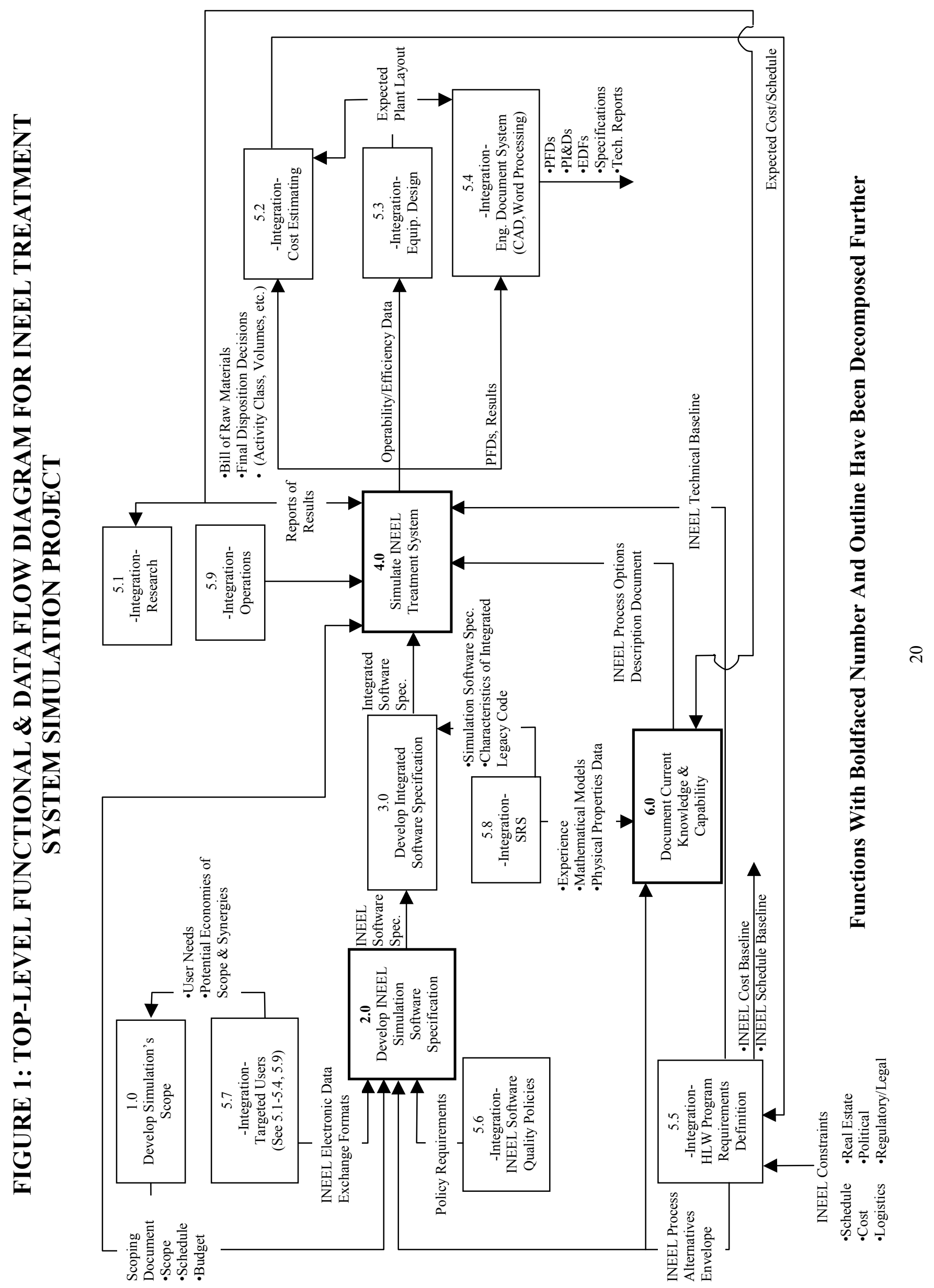




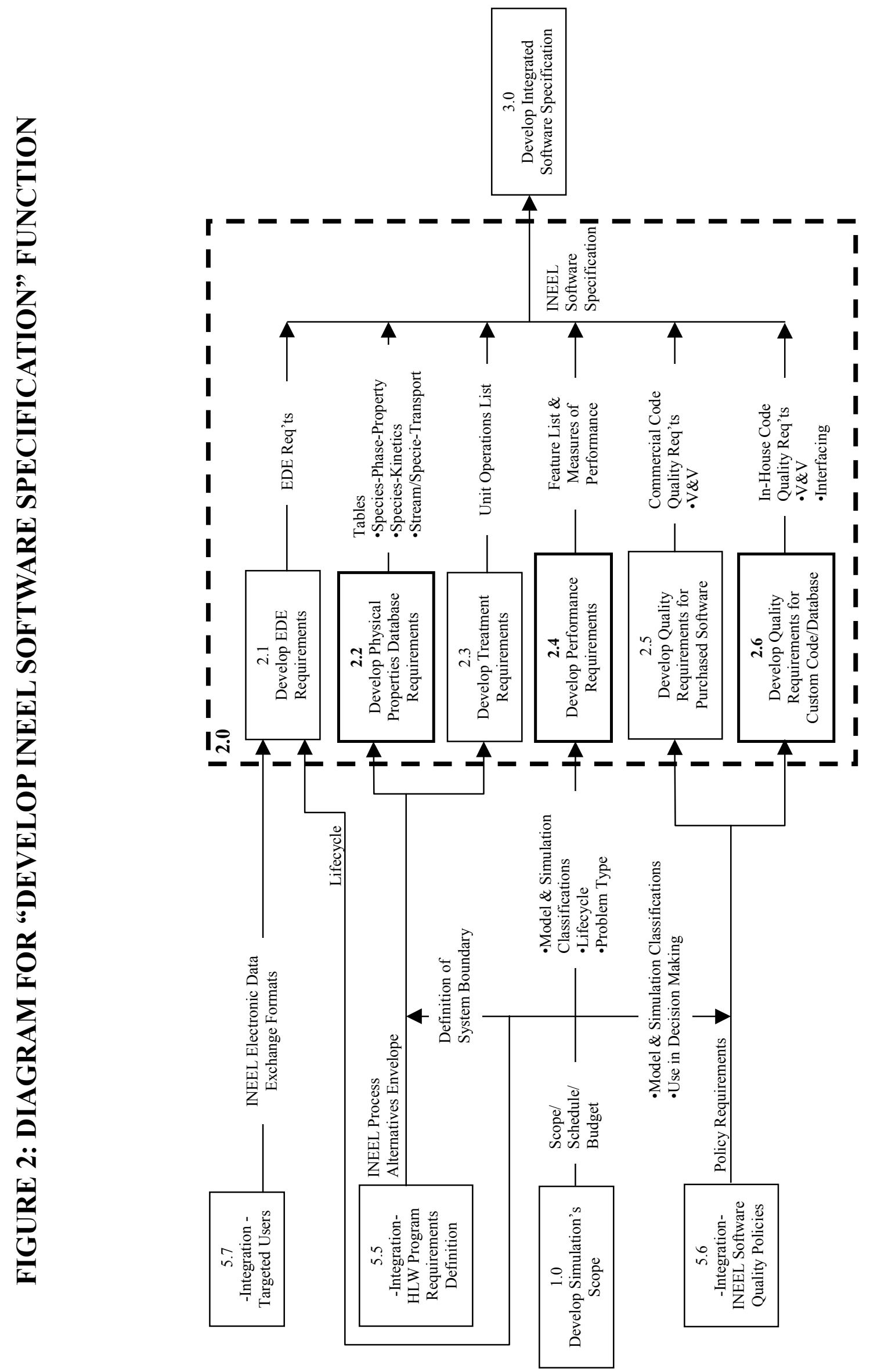




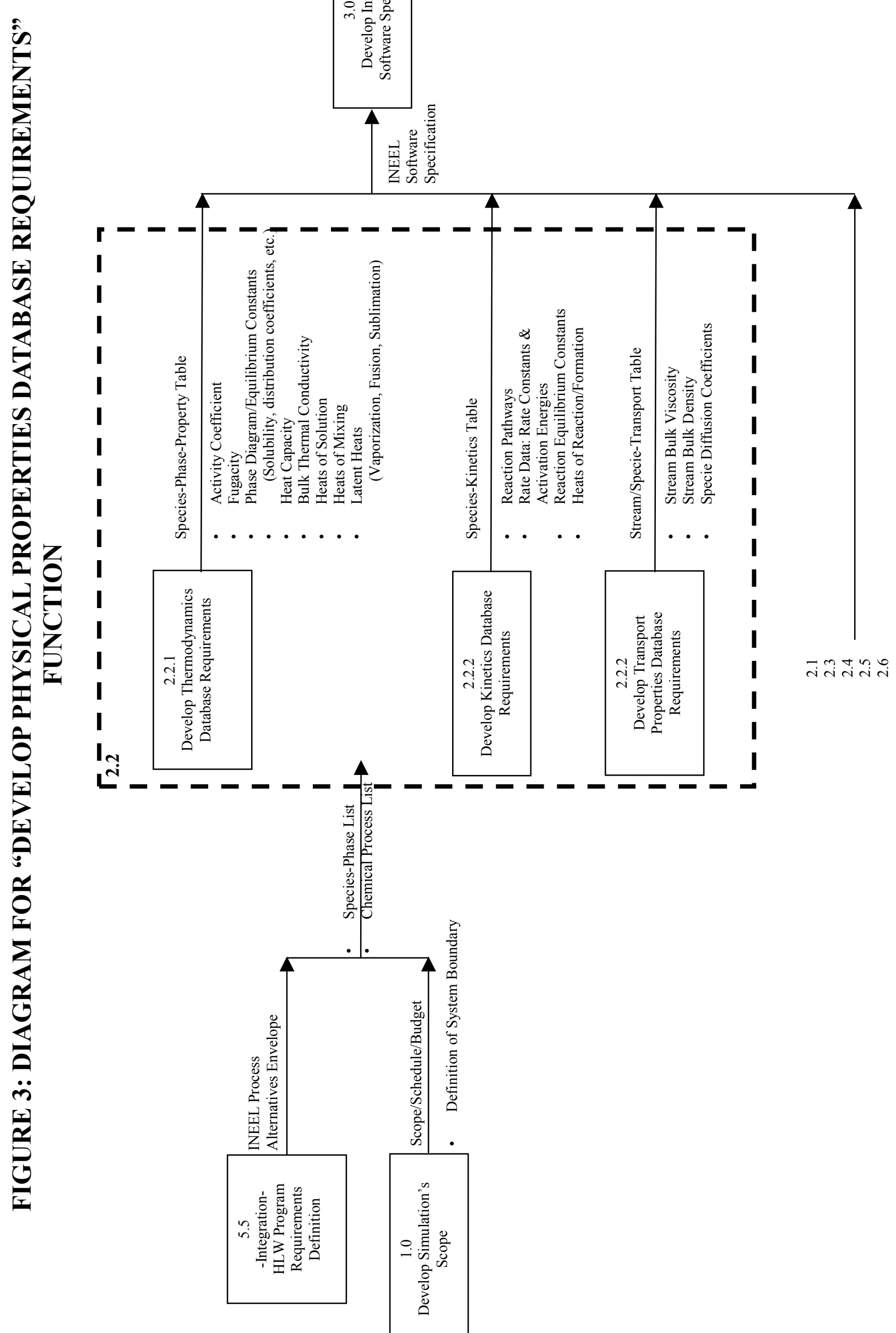




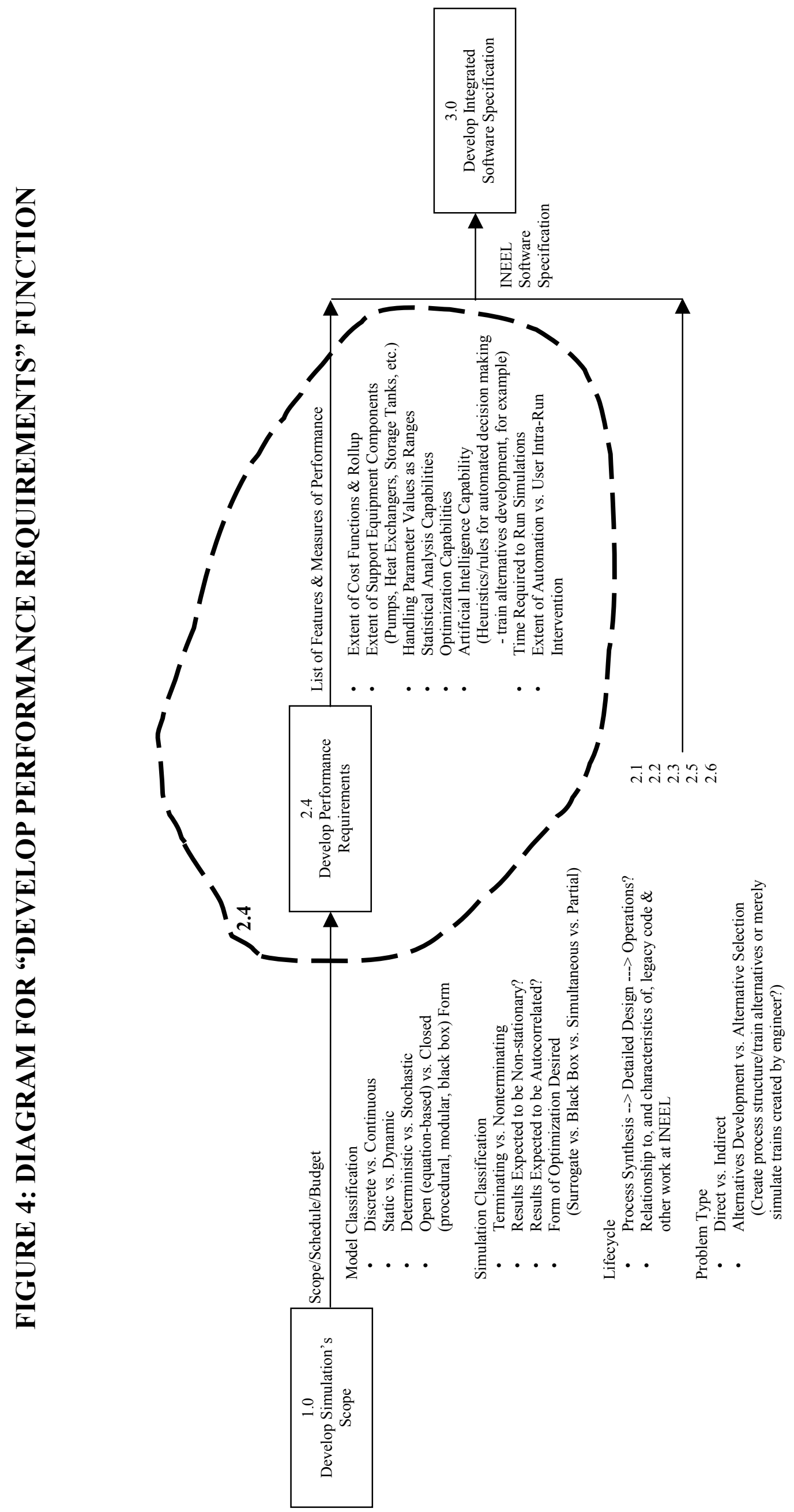




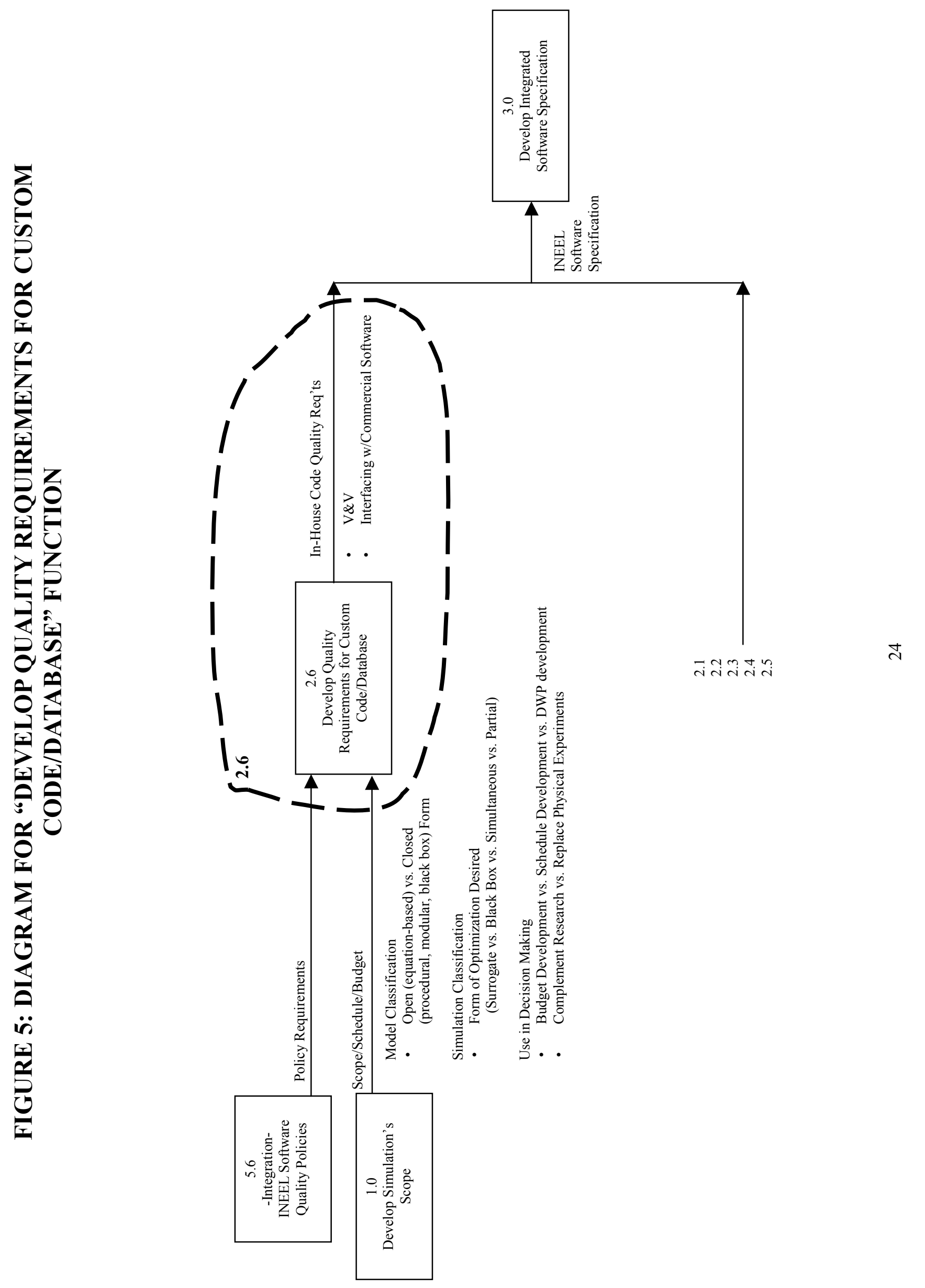




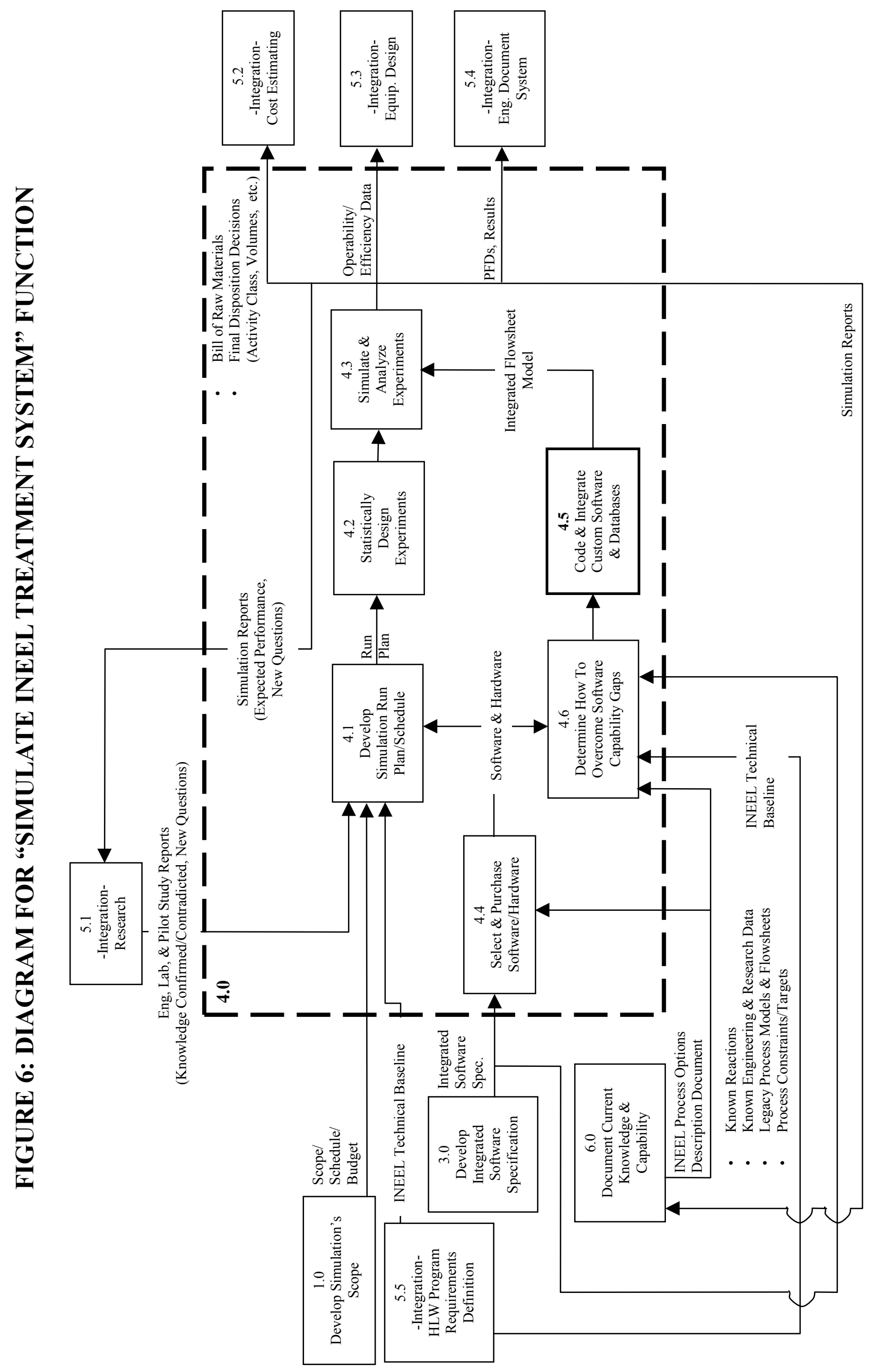




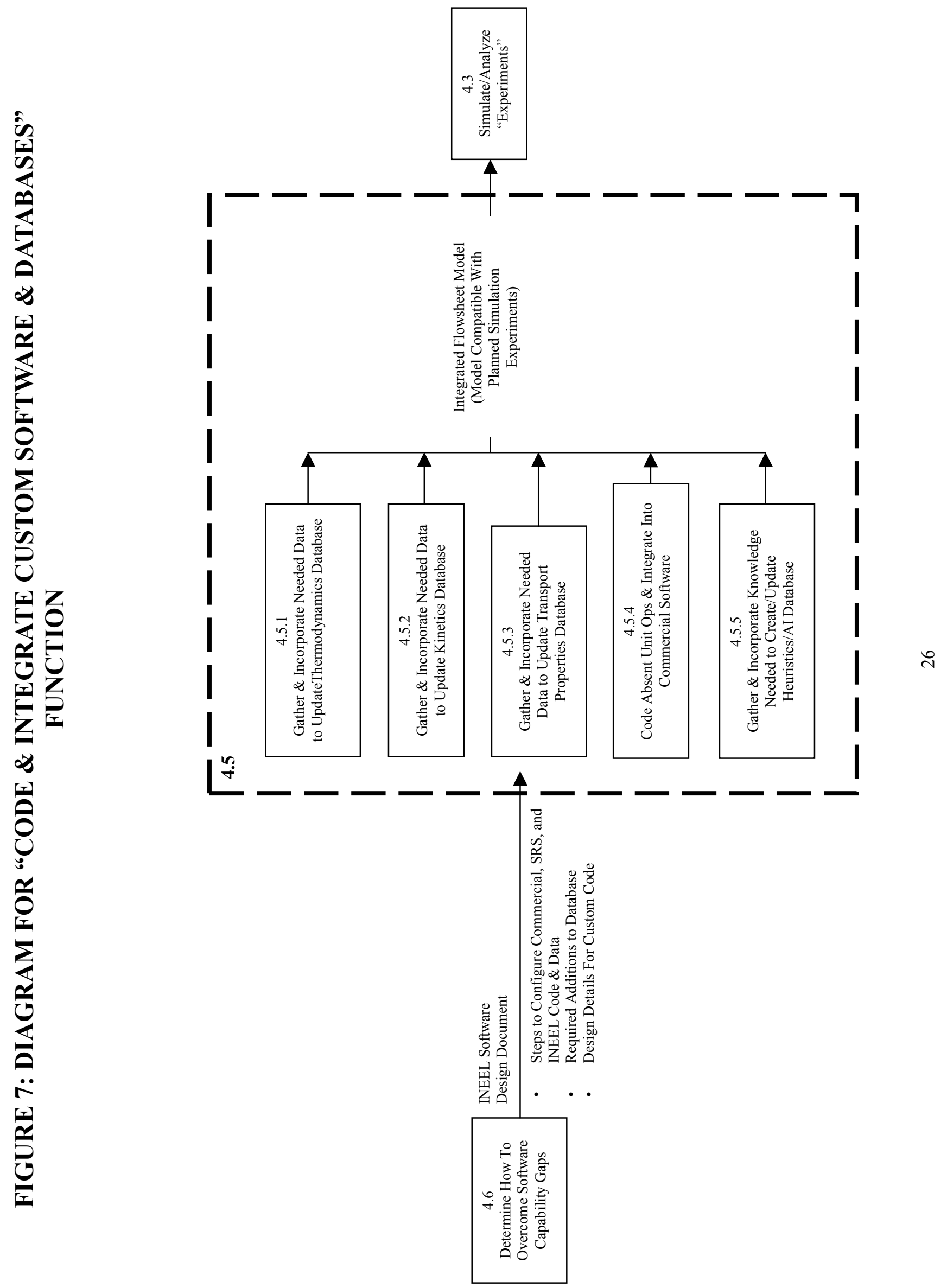




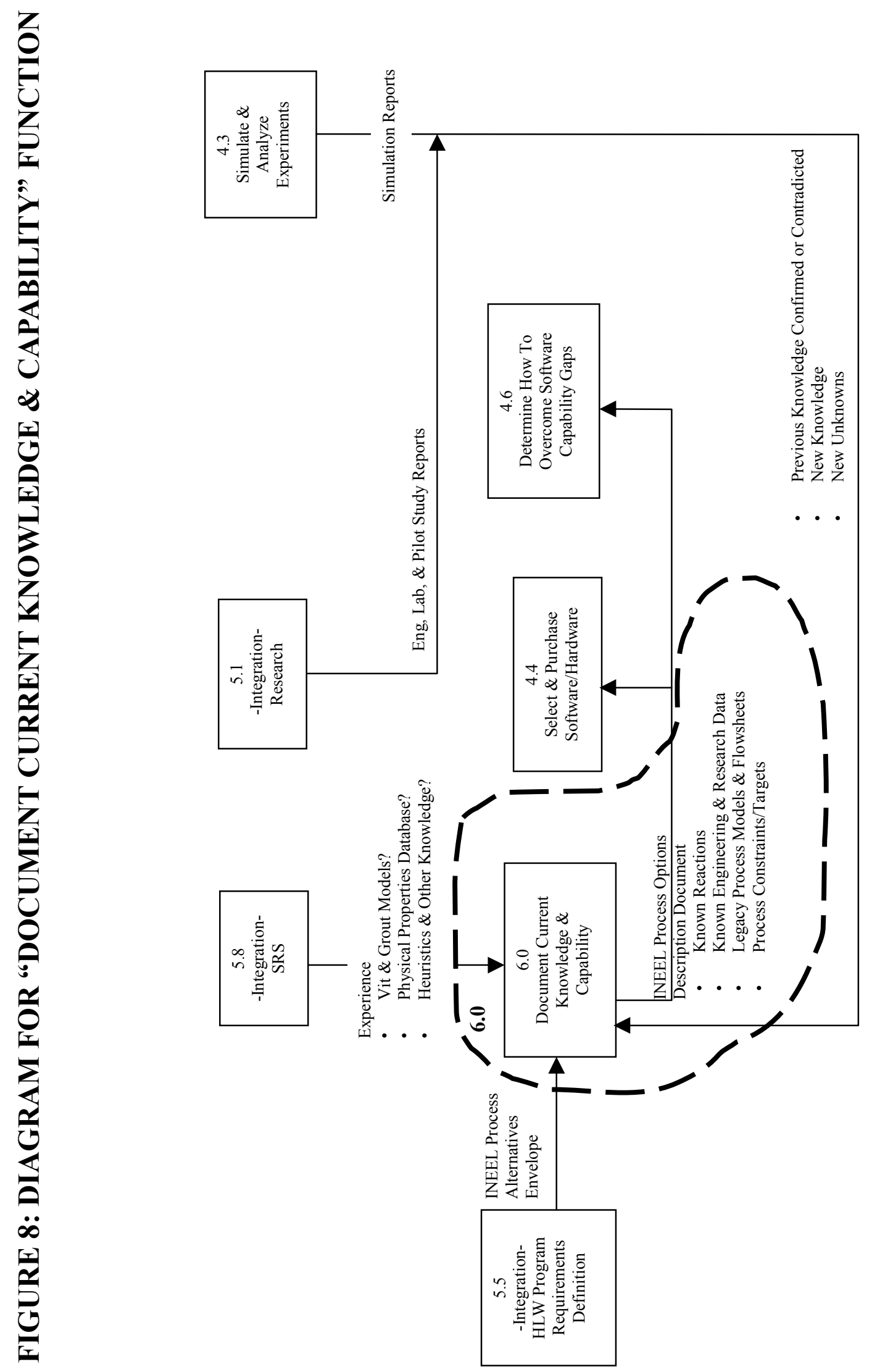

ก 


\section{REFERENCES}

Barnes, Charles (2000), E-mail to T.T. Nichols, D.D. Taylor, and L. Lauerhass, Process Alternatives Envelope, October 30.

Bourseau, L. Valadou and G. Muratet (1994), "Coupling Intervals Constraint Propagation And Assumptions-Based Reasoning For Flowsheet Analysis," Computers \& Chemical Engineering, Vol. 18, Supplement, pp. S289-S293.

Law, Averill M. and W. David Kelton (1991), Simulation Modeling \& Analysis, $2^{\text {nd }}$ Edition, McGraw Hill, San Francisco.

Marquardt, Wolfgang, Lars von Wedel, and Birgit Bayer (2000). "Perspectives on Lifecycle Process Modeling," Fifth International Conference on Foundations of Computer-Aided Process Design, AIChE Symposium Series, Vol. 96, No. 323, pp. 192-214.

Nichols, Todd (2000a), Letter to C.A. Barnes, L. Lauerhass, A.L. Olson, and D.D. Taylor, INEEL HLW Process Alternatives Envelope, TTN-02-00, October 19.

Nichols, Todd (2000b), E-mail to A.L. Olson, C.M. Barnes, L. Lauerhass, D.D. Taylor, L.L. Simmons, J.D. Christian, and N. Hutson (Savanna River Site), MINUTES OF TTP PLANNING MEETING BETWEEN SRS \& INEEL -10/25/00, November 1. Copy accessible from Document Control Center for INEEL, Applied Technology, Organization 3330.

Raytheon Engineers \& Constructors (2000), Idaho National Technology \& Engineering Center Sodium Bearing Waste (SBW) Treatment Facility Project: CsIX/TRU Grout Process FY2000 Feasibility Study Report, Volume I: Feasibility Study Report and Appendix A, Section 2: Feasibility Study Summary, Idaho National Engineering and Environmental Laboratory, U.S. Department of Energy, Idaho Operations Office, September.

Schug, Brett W. and Matthew J. Realff (1998), "Analysis of waste vitrification product-process systems," Computers \& Chemical Engineering, Vol. 22, No. 6, pp. 789-800.

Second Modification (1998), Second Modification to Consent Order to the Notice of Noncompliance issued January 29, 1990, IN THE MATTER OF United States Department of Energy and Idaho National Engineering and Environmental Laboratory, August 18.

Settlement Agreement (1995), Court Order entered into by the State of Idaho, U.S. Department of Energy, and U.S. Department of the Navy in the United States District Court For The District Of Idaho, October 17. 